\title{
Wrist-ankle acupuncture attenuates cancer-induced bone pain by regulating descending pain-modulating system in a rat model
}

\author{
Chunpeng Zhang ${ }^{1 \dagger}$, Chen $\mathrm{Xia}^{1+}$, Xiaowen Zhang ${ }^{1}$, Weimin $\mathrm{Li}^{2}$, Xuerong Miao ${ }^{3^{*}}$ and Qinghui Zhou ${ }^{1 *}$
}

\begin{abstract}
Background: Cancer-induced bone pain (CIBP) presents a multiple-mechanism of chronic pain involving both inflammatory and neuropathic pain, and its pathogenesis is closely related to endogenous descending system of pain control. However, the action mechanism underlying the effects of wrist-ankle acupuncture (WAA) versus electroacupuncture (EA) on CIBP remains unknown.

Methods: Thirty-two Wistar rats were divided into sham, CIBP, EA-treated and WAA-treated groups. CIBP was induced in rats of the latter three groups. Time courses of weight and mechanical hyperalgesia threshold (MHT) were evaluated. After 6 days of EA or WAA treatment, the expressions of 5-hydroxytryotamine type $3 \mathrm{~A}$ receptor $\left(5-\mathrm{HT}_{3 \mathrm{~A}} \mathrm{R}\right)$ and $\mu$-opioid receptor (MOR) in rostral ventromedial medulla (RVM) and/or spinal cord, as well as the levels of 5-HT, $\beta$-endorphin, endomorphin-1 and endomorphin-2 in RVM and spinal cord, were detected.

Results: Injection of cancer cells caused decreased MHT, which was attenuated by EA or WAA $(P<0.05)$. WAA had a quicker analgesic effect than EA $(P<0.05)$. No significant difference of MOR in RVM was found among the four groups. EA or WAA counteracted the cancer-driven upregulation of $5-\mathrm{HT}_{3 \mathrm{~A}} \mathrm{R}$ and downregulation of $\mathrm{MOR}$ in spinal cord $(P<0.05)$, and upregulation of 5-HT and downregulation of endomorphin-1 in both RVM and spinal cord $(P<0.05)$. $\beta$-endorphin and endomorphin-2 in RVM and spinal cord decreased in CIBP group compared with sham group $(P<0.05)$, but EA or WAA showed no significant effect on them, although a tendency of increasing effect was observed.

Conclusion: WAA, similar to EA, alleviated mechanical hyperalgesia in CIBP rats by suppressing the expressions of 5-HT and 5-HT $3{ }_{3 A} \mathrm{R}$, and increasing the expressions of MOR and endomorphin-1 in RVM-spinal cord pathway of the descending pain-modulating system. However, WAA produced a quicker analgesic effect than EA, the mechanisms of which need further investigation.
\end{abstract}

Keywords: Wrist-ankle acupuncture, Electroacupuncture, Cancer pain, Descending modulation

*Correspondence: miaoxr@smmu.edu.cn; qinghui2016@163.com

${ }^{\dagger}$ Chunpeng Zhang and Chen Xia contributed equally to this work

${ }^{1}$ School of Traditional Chinese Medicine, Changhai Hospital, Naval Medical University, 168 Changhai Road, Shanghai 200433, People's Republic of China

${ }^{3}$ Department of Anesthesiology, Eastern Hepatobiliary Surgery Hospital, Naval Medical University, 225 Changhai Road, Shanghai 200433, People's Republic of China

Full list of author information is available at the end of the article

\section{Background}

Cancer-related pain, caused by bone metastasis from malignant tumors, is the most common and extremely devastating symptom that decreases quality of patients' life; more than $70 \%$ of patients with advanced cancer have suffered from cancer-induced bone pain (CIBP) [1, 2]. Opioids remain the mainstay of clinical drug treatment

(c) The Author(s) 2020. This article is licensed under a Creative Commons Attribution 4.0 International License, which permits use, sharing, adaptation, distribution and reproduction in any medium or format, as long as you give appropriate credit to the original author(s) and the source, provide a link to the Creative Commons licence, and indicate if changes were made. The images or other third party material in this article are included in the article's Creative Commons licence, unless indicated otherwise in a credit line to the material. If material is not included in the article's Creative Commons licence and your intended use is not permitted by statutory regulation or exceeds the permitted use, you will need to obtain permission directly from the copyright holder. To view a copy of this licence, visit http://creativeco mmons.org/licenses/by/4.0/. The Creative Commons Public Domain Dedication waiver (http://creativecommons.org/publicdomain/ zero/1.0/) applies to the data made available in this article, unless otherwise stated in a credit line to the data. 
for CIBP, often in combination with initial radiotherapy and adjuvant agents inhibiting osteoclast activity [3-6]. However, only half patients with CIBP gain temporary pain relief from conventional analgesics, and new and better therapies for CIBP alleviation with few adverse effects are urgently required $[7,8]$.

Wrist-ankle acupuncture (WAA) is a modern acupuncture therapy performed through the subcutaneous insertion of needles at points on the wrist and ankle regions. WAA theory is quite different from that of traditional acupuncture, and this treatment does not induce any pain or "needling sensation", an unpleasant feeling such as local fullness, numbness, and soreness [9-11]. Due to its wide range of analgesic effects for various pain states, WAA is easily accepted by patients with cancer-related pain. Previously, our team examined the analgesic efficacy of WAA for patients with hepatocarcinoma-induced pain, and its analgesic mechanism has also been discussed in our series of studies [12-15].

CIBP presents a multiple-mechanism of chronic pain involving both inflammatory and neuropathic pain, and often occurs at more than one site due to tumor expansion, causing damage to the primary afferent nerve fibers of bone and releasing various inflammatory mediators $[16,17]$. The rostral ventromedial medullar (RVM) in brain plays a crucial role in the endogenous descending system of pain control, exerting pain inhibitory/facilitatory actions [18-20]. Previous evidence has suggested that the predominant RVM descending modulating system impacts central sensitization and magnification of the pain response in the spinal cord when chronic pain persists [21-23].

Electroacupuncture (EA) has been found to be effective for relieving various pain states including cancer pain, and its analgesic effect on animal with CIBP has been examined in recent studies [24, 25]. EA with lowerfrequency $(2 \mathrm{~Hz})$ stimulates $\beta$-endorphin $(\beta-\mathrm{EP})$ and endomorphin (EM) release, which activates $\mu$-opioid receptor (MOR) in brain, and EA with higher-frequency $(100 \mathrm{~Hz})$ stimulates dynorphin, which activates MOR in the spinal cord [26-28]. Combination of these two frequencies results in the simultaneous release of all these substances, leading to a maximal analgesic efficacy. Several studies have suggested that the analgesic mechanism of EA might be connected with the inhibitory/facilitatory descending system of pain, especially with MOR and 5-hydroxytryotamine (5-HT) in the RVM-spinal cord pathway [29-32]. However, no animal experiments studying the mechanism of WAA for regulating CIBP have been performed to date.

Stimulation with WAA is quite different to EA stimulation, and it is unknown whether the mechanism of WAA is similar or different to that of EA. We hypothesized that WAA, as EA, would inhibit CIBP by mediating the descending pain inhibitory/facilitatory system. Therefore, in this study, by establishing a CIBP rat model, we investigated the effect of WAA on CIBP by experimental methods such as praxeology and molecular biology and compared the analgesic mechanisms of WAA and EA on CIBP.

\section{Materials and methods}

\section{Animals and grouping}

Thirty-two specific pathogen-free grade female Wistar rats weighing $140-160 \mathrm{~g}$ for establishment of the animal model, and three weighing $70 \mathrm{~g}$ for ascites passage of tumor cells, were purchased from Shanghai Slac Laboratory Animal Co., Ltd. (Shanghai, China; No. SCXK $[\mathrm{Hu}] 2007-0001)$. The animals were maintained at the Animal Experimentation Center of Changhai Hospital in a controlled environment of $20-24{ }^{\circ} \mathrm{C}$, with a $50 \%-70 \%$ humidity range, a $12 \mathrm{~h}$ light/dark cycle, with food and water ad libitum. The study protocol and experiments were approved by the Animal Care and Use Committee of Naval Medical University. Walker 256 mammary cancer cells were obtained from Shanghai Biomedical Engineering Research Center.

After 3 days of adaptive feeding, the 32 rats for establishment of the animal model were randomly divided into four groups with eight rats in each group: sham, CIBP, CIBP plus EA, and CIBP plus WAA groups. Body weights were measured every day. All rats were euthanized on day 16 (D 16), and the sample of ipsilateral spinal cord and RVM were excised according to the rat brain atlas for further study [33]. Four rats in each group were randomly selected for molecular experiment, and the other 4 rats in each group were transcardially perfused with $4 \%$ paraformaldehyde for immunohistochemical staining. The sample of relevant tissues was diluted 10 times with PBS after homogenation for different experiments.

\section{Induction of bone cancer pain}

Bone cancer pain was induced in rats according to the methods described in previous studies [34, 35]. Briefly, intraperitoneal injection of Walker 256 mammary cancer cells was performed on the rats, and then the ascites was collected on day 7 after injection. The cell density was adjusted to $1 \times 10^{5} / \mu \mathrm{L}$. Thermal-inactivated cancer cells were also prepared. After sterilizing the shaved left hind limb, the cancer cells $\left(4 \times 10^{5}\right.$ cells in $\left.10 \mu \mathrm{L}\right)$ were injected into the medullary cavity of the left tibia through the tibial plateau using a microsyringe $(10 \mu \mathrm{L}$; Hamilton Co, Bonaduz, Switzerland) to induce bone cancer in the rats, and the injection hole was quickly sealed with bone wax. Equivalent thermal-inactivated cancer cells were performed through a similar process in the sham group. 


\section{Acupuncture treatments}

For acupuncture treatments, Hwato brand disposable acupuncture needles $(0.16 \mathrm{~mm} \times 7 \mathrm{~mm}$; Suzhou Medical Appliance Factory, Suzhou, China) and SDZ-V EA apparatuses (Nerve and Muscle Stimulator SDZ-V; Suzhou Medical Appliance Factory, Suzhou, China) were used.

Two acupoints, Zusanli (ST36, located at one-fifth point below and lateral to the anterior tubercle of the tibia) and Kunlun (BL60, located at the depression posterior to the lateral malleolus of tibiofibula), were commonly used for EA treatment of cancer pain in animal studies [32, 36] (Fig. 1a). In this study, rats in the EA group received acupuncture at left ST36 and BL60 with needle insertion approximately $4 \mathrm{~mm}$ into the skin (Fig. 1a). Paired electrodes from the EA apparatus were attached to the needle handles. The EA stimulation was applied for $30 \mathrm{~min}$ with a dense-disperse wave of $2 / 100 \mathrm{~Hz}$ and a current intensity of $2 \mathrm{~mA}$.

In the WAA group, rats were needled at Lower Point 5 (the same location of BL60) at the left hind limb, subcutaneously towards the surgical site [10] (Fig. 1b). The needle remained with a tape in the superficial layer of the subcutaneous tissue until 8:00 the next day.

All treatments were started at 16:00-17:00 of day 10 after the induction of bone cancer pain, once a day for 6 continuous days.

Rats in the sham and CIBP groups did not receive acupuncture intervention. Rats in all four groups wore a selfmade headgear from 16:00 to 8:00 the next morning to prevent biting [37]. In order to limit the rat activity during treatment proceeding, rats in all groups were fixed properly at the time of EA treatment.

\section{Measurement of pain behavior}

The 50\% paw withdrawal threshold (PWT) of the rats was measured using the up-down method of Dixon [38], and was performed during 10:00-14:00 before the injection of the cancer cells (baseline), at every other day after the injection (D1, D3, D5, D7, and D9), and during 17:0018:00 after the treatments of each group, at every other day when intervention involved (D11, D13, and D15). The experimental process is shown in Fig. 2. For von Frey testing, a cellosilk probe called von Frey filament (Stoelting, IL, USA) was used to poke the hind paw pad with a sufficient upward force. A positive response was noted if the hind paw was sharply withdrawn, and the value of the final von Frey filament was recorded for calculation. The testing was repeated 8 times at 3-min intervals, and the target force values ranged $0.4-15$ were used to prevent damage. 50\% PWT value was conversed by the following formula [39]:

$$
50 \% \mathrm{PWT}=\left(10^{\left[X_{f}+k \delta\right]}\right) / 10,000
$$

where $X_{f}=$ value (in log units) of the final von Frey filament used; $k=$ tabular value for the pattern of positive/ negative responses; and $\delta=$ mean difference (in log units) between stimuli.

\section{Hematoxylin and eosin staining}

For histopathological examination, left tibias were extracted at day 16 (D16), fixed in $10 \%$ neutral buffered formalin for $48 \mathrm{~h}$, and then decalcified in ethylenediaminetetraacetic acid. Then the adequately decalcified tibias followed a regular hematoxylin and eosin staining
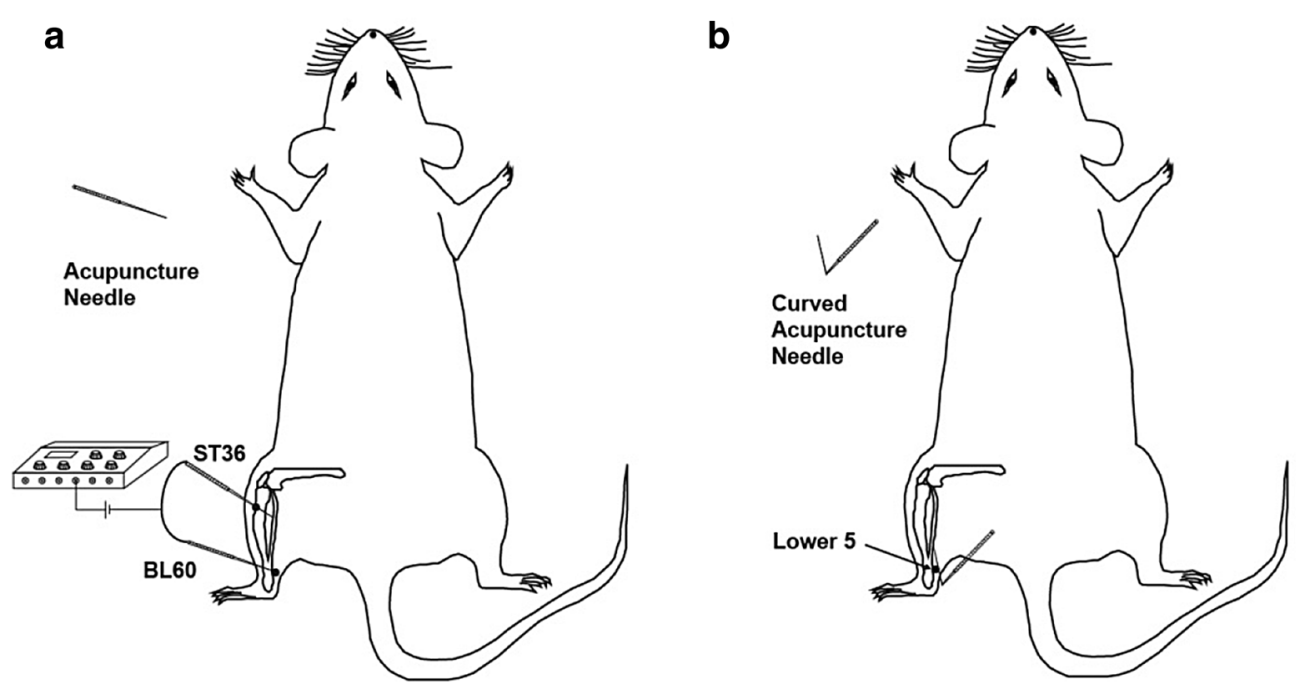

Fig. 1 Needling of electroacupuncture (EA) and wrist-ankle acupuncture (WAA) at the hind limb. a Electroacupuncture of ST36 and BL60; b wristankle acupuncture of Lower Point 5 


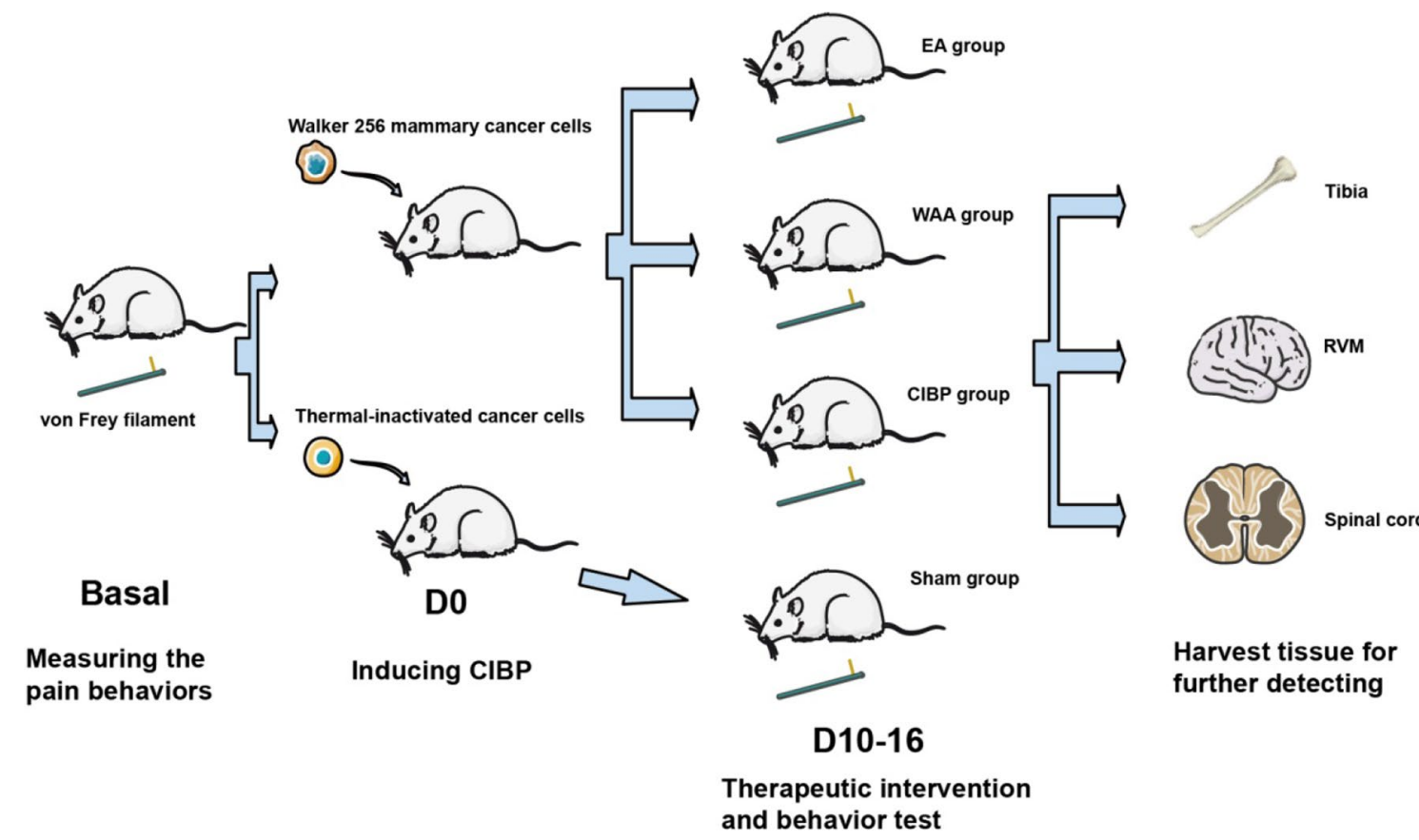

Fig. 2 Experimental protocol for the assessment of pain. CIBP cancer-induced bone pain

process [40]: dehydration, transparency, embedding, slicing, incubating, dewaxing, and washing. These sections were stained with hematoxylin and eosin, and the slices were examined using light microscopy.

\section{Real-time polymerase chain reaction}

The mRNA expression levels of $5-\mathrm{HT}_{3 \mathrm{~A}} \mathrm{R}$ and MOR within the spinal cord and RVM, were measured by realtime polymerase chain reaction (PCR) as described [41]. More specifically, samples were prepared by homogenization with TRIzol reagent (Invitrogen, Carlsbad, CA) and RNA was extracted according to the instructions. Next, reverse transcription (RT) was performed to convert RNA into cDNA using the RT premix kit (Thermo, Waltham, MA, US) with oligo DT primers. Real-time PCR was performed using $2 \mu \mathrm{L}$ of cDNA with SYBRGreen PCR Mix plus (Thermo, Waltham, MA, USA). The primers for real-time PCR were as follows: MOR primer, 5'-ACCGTTTCCTGGCACTTC-3' and antisense primer, 5'-GTATTAGCCGTGGAGGGATG-3'; 5- $\mathrm{HT}_{3 \mathrm{~A}} \mathrm{R}$ primer, 5'-AAGAAGTGAGGT CGGACAAGAG-3 and antisense primer, 5'-GGCTGACTGCGTAGAATAAAGG-3'; Glyceraldehyde-3-phosphate dehydrogenase (GAPDH) primer, 5'-TGGGCAAGGTCATCCCA GAG-3', and antisense primer 5'-GAGGCCATGTAGGCCATGAG-3'.

The standard cycling conditions were as follows: initial denaturation $\left(95{ }^{\circ} \mathrm{C}\right.$ for $3 \mathrm{~min}$ ), followed with 40 cycles involving denaturation $\left(95^{\circ} \mathrm{C}\right.$ for $\left.15 \mathrm{~s}\right)$, annealing $\left(60{ }^{\circ} \mathrm{C}\right.$ for $\left.60 \mathrm{~s}\right)$, and extension $\left(60{ }^{\circ} \mathrm{C}\right.$ for $\left.15 \mathrm{~s}\right)$. Relative fold changes of gene expression were analyzed using the $\Delta \Delta \mathrm{CT}$ method by ABI Prism 7300 SDS software, and the values are expressed as $2^{-\Delta \Delta C t}$.

\section{Western blotting}

Western blotting followed a previously described procedure [42]. In brief, spinal cord and RVM samples were lysed in lysis buffer containing a protease inhibitor cocktail (Jrdun Biotech, Shanghai, China). The proteins were separated on 10\% SDS-polyacrylamide gels (Jrdun Biotech, Shanghai, China) and transferred to polyvinylidene difluoride (PVDF) membranes (Jrdun Biotech, Shanghai, China). The blots were probed with primary antibodies against MOR (rabbit anti-MOR; 1:1000; Abcam, Cambridge, Shanghai, China) or $5-\mathrm{HT}_{3 \mathrm{~A}} \mathrm{R}$ (rabbit anti5- $\mathrm{HT}_{3 \mathrm{~A}} \mathrm{R} ; 1$ 1:200; Abcam, Cambridge, Shanghai, China), and horseradish peroxidase (HRP)-conjugated secondary antibody (goat anti-rabbit; 1:1000; Beyotime Biotech, Shanghai, China). According to the enhanced chemiluminescence (ECL) method, gray value was measured by Image J software with GAPDH as control.

\section{Immunohistochemical staining}

Rats were euthanized with $4 \%$ paraformaldehyde perfused transcardially in PBS (Jrdun Biotech, Shanghai, China) at $\mathrm{pH}$ 7.4. The brain and lumbar spinal cord (L4-L6) were cut into $7 \mu \mathrm{m}$ slices, which were 
immunohistochemically stained as previously described [20]. Images of the stained slices were captured under a phase-contrast microscope $(200 \times$ magnification $)$ and the images were saved in ProgRes Capture Pro 2.7 Image analysis software (Jenoptik, Germany). The areas of $5-\mathrm{HT}_{3 \mathrm{~A}} \mathrm{R}$ and MOR expression in these sections, which corresponded to the superficial part of the spinal cord and RVM, were selected by Image Pro Plus software to calculate the positive ratio (positive ratio $=$ positive area/ observed area).

\section{Enzyme-linked immunosorbent assay}

Levels of 5-HT, $\beta$-EP, endomorphin-1 (EM-1), and endomorphin-2 (EM-2) were determined using a sandwich enzyme-linked immunosorbent assay (ELISA) system. Samples were prepared by homogenization of the spinal cord or RVM in PBS (pH 7.4, $6{ }^{\circ} \mathrm{C}$ ), and then collected through centrifugation $(2500 \times g$ for $20 \mathrm{~min})$. The supernatants were collected, and antigen levels were measured using corresponding ELISA kits (R\&D Systems, Minneapolis, MN, USA) following the instructions.

\section{Statistical analysis}

All statistical analyses were performed using SPSS 21.0, and Graphpad Prism 6 was used to create graphs. All data were described as mean \pm standard deviations. For $50 \%$ PWTs, the differences were examined by a two-way analysis of covariance with repeated measurements. For other data, one-way analysis of variance (ANOVA) followed by a Dunnett's test was used for the comparison of groups. $P$ value less than 0.05 was regarded as statistically significant.

\section{Results}

\section{Weight of the rats}

Before EA and WAA intervention and on D6 after cancer cell injection, rats in the three model groups (CIBP, EA, and WAA groups) lost weight, and there were no significant differences in weight gain among the three groups. From D14 to D16, the rat weights of the EA and WAA groups were higher than that of the CIBP group, which showed no tendency to increase $(P<0.05$, Fig. 3a). No significant differences in rat weights were observed between the EA and WAA groups throughout the experiment $(P>0.05$, Fig. 3a).

\section{Mechanical hyperalgesia threshold}

Figure $3 \mathrm{~b}$ shows the effects of EA and WAA on $50 \%$ PWT of the ipsilateral hind paw of CIBP rats. Before inoculation of cancer cells (Basal), no significant differences were found in PWT among four groups $(P>0.05)$. The PWT in the three model groups (CIBP, EA, and WAA groups) decreased significantly from D7, with significant differences compared with the sham group $(P<0.05)$, but no significant differences were found among the CIBP, EA, and WAA groups on D7 and D9 $(P>0.05)$. On D11 and D13, WAA treatment significantly increased the PWT compared with the CIBP and EA groups $(P<0.05)$, indicating that WAA treatment could increase the mechanical hyperalgesia threshold (MHT). On D15, the PWT showed a significant increase in EA, but no difference found between the EA and WAA groups, indicating that WAA treatment produced a quick effect in increasing MHT and had a long-term effect equal to EA treatment.
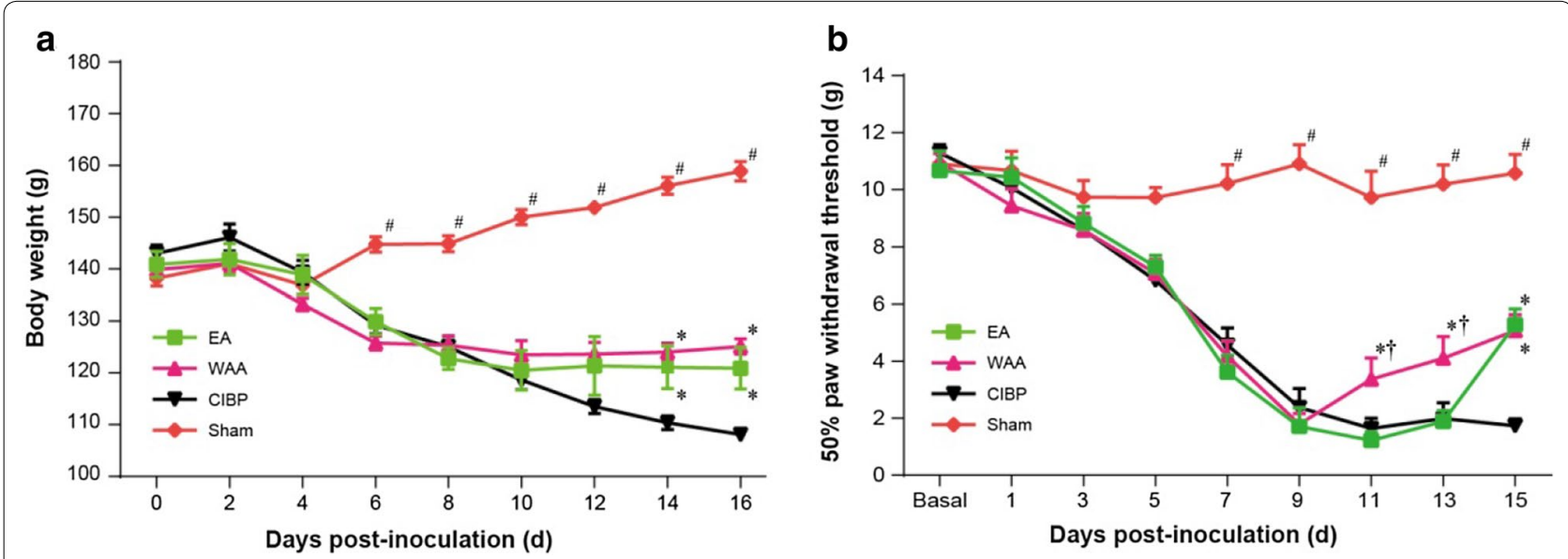

Fig. 3 Effects of WAA on rat weight and ipsilateral 50\% paw withdrawal threshold. a Effects of WAA on rat weight; $\mathbf{b}$ Effects of WAA on ipsilateral $50 \%$ paw withdrawal threshold. Values are mean \pm standard deviations $(n=8)$. ${ }^{*} P<0.05$ vs. CIBP group; ${ }^{P} P<0.05$ vs. model groups (CIBP, EA, and WAA groups). CIBP cancer-induced bone pain, EA electroacupuncture, WAA wrist-ankle acupuncture 


\section{Observation of tibial tissue}

The hematoxylin and eosin-stained sections of the ipsilateral tibia from the sham group indicated healthy marrow without tumor growth and bone destruction. Sections of the ipsilateral tibias from all tumor cell-injected groups indicated abnormal polynuclear tumor cell replacement in the bone marrow cavity. The trabecular bones were widely eroded, and many braided bone formations were observed in the model group (Fig. 4).

\section{Analgesic mechanism of WAA \\ Effects of WAA and EA on 5-HT ${ }_{3 A} R$ mRNA and protein expression in the spinal cord}

In the CIBP, EA, and WAA groups, the levels of $5-\mathrm{HT}_{3 \mathrm{~A}} \mathrm{R}$ mRNA and protein in the corresponding segment of spinal cord were significantly higher than that in the sham group $(P<0.05)$. 5- $\mathrm{HT}_{3 \mathrm{~A}} \mathrm{R} \mathrm{mRNA}$ and protein levels were significantly lower in the EA and WAA groups than that in the CIBP group $(P<0.05)$, but no difference was found between these treatment groups $(P>0.05)$, as shown in Fig. 5a1-3. The results indicated that EA and WAA treatment could decrease the expression levels of $5-\mathrm{HT}_{3 \mathrm{~A}} \mathrm{R}$ in the spinal cord.

\section{Effects of WAA and EA on MOR mRNA and protein expressions within the spinal cord and RVM}

In the corresponding segment of spinal cord, there were significantly lower MOR mRNA and protein expressions $(P<0.05)$ in the three tumor-injected groups than in the sham group $(P<0.05)$, and more MOR mRNA and protein was found in the EA and WAA groups than in the CIBP group, but no significant difference was found between these two groups $(P>0.05)$, as shown in Fig. 5b1-3. But in the RVM (Fig. 5c1-3), the expression levels of MOR mRNA and protein showed no significant difference among four groups $(P>0.05)$.

\section{Immunohistochemical results of $5-H_{3 A} R$ and MOR}

$5-\mathrm{HT}_{3 \mathrm{~A}} \mathrm{R}$ and MOR in spinal cord are mainly located in the in the superficial layers of the dorsal horn (SDH), where nociceptive stimuli are expressed. The positive ratios of $5-\mathrm{HT}_{3 \mathrm{~A}} \mathrm{R}$ in the spinal cords of the three model groups (CIBP, EA, and WAA groups) were substantially higher than in the sham group $(P<0.05)$. Among the three model groups, the positive ratios of $5-\mathrm{HT}_{3 \mathrm{~A}} \mathrm{R}$ in the EA and WAA groups were significantly lower than that in the CIBP group $(P<0.05)$, but no significant difference was found between the EA and WAA groups $(P>0.05)$, as shown in Fig. 6a1, 2.

The positive ratios of MOR in the spinal cord of the three model groups (CIBP, EA, and WAA groups) were substantially lower than in sham group $(P<0.05)$. Among the three model groups, the positive ratios of MOR in the EA and WAA groups were significantly higher than that in the CIBP group $(P<0.05)$, but no significant difference was found between the EA and WAA groups $(P>0.05)$, as shown in Fig. 6b1, 2.

The staining of MOR in the RVM showed no difference among the four groups $(P>0.05$; Fig. $6 \mathrm{c} 1,2)$.

\section{ELISA results of 5-HT, $\beta-E P, E M-1$, and EM-2}

After the rats were killed, the levels of 5-HT, $\beta$-EP, EM-1, and EM-2 within the spinal cord and RVM were detected by ELISA. Compared with the CIBP group, the

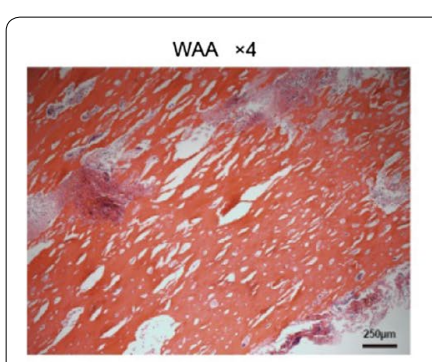

WAA $\times 10$

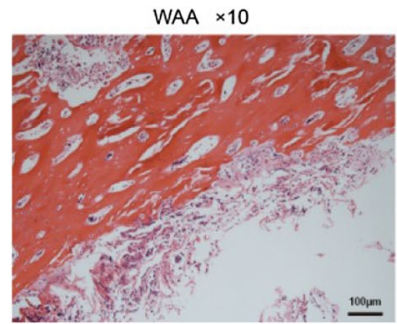

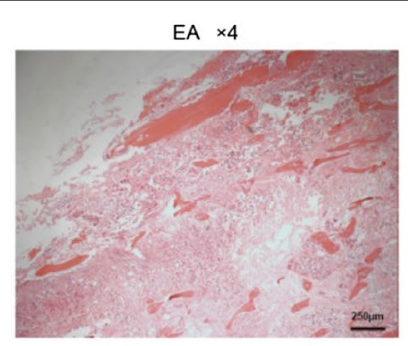

$\mathrm{EA} \times 10$

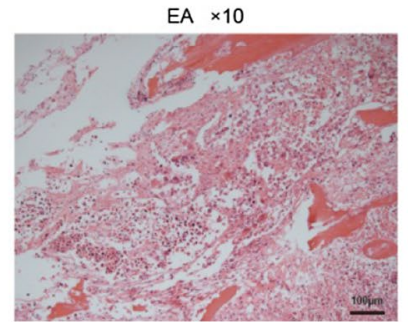

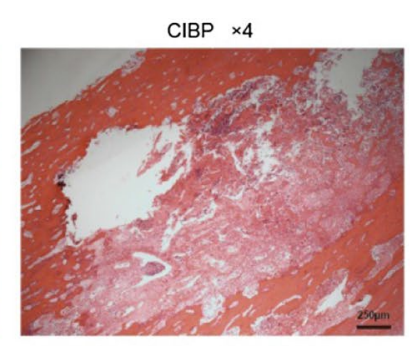

CIBP $\times 10$

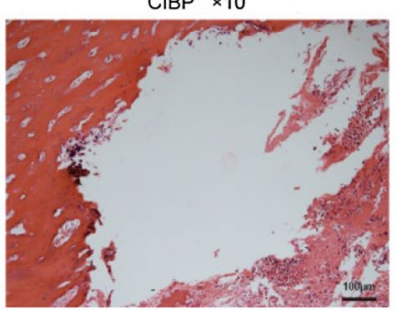

Sham $\times 4$

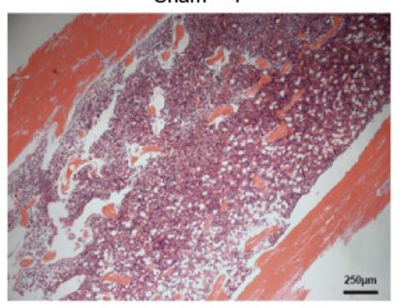

Sham $\times 10$

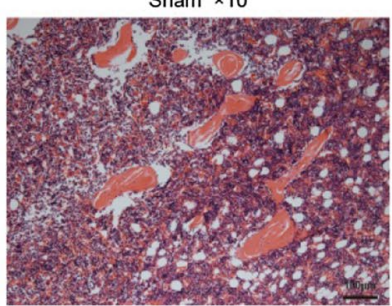

Fig. 4 Tissue destruction of tibia in rats of the four groups stained with hematoxylin and eosin. CIBP cancer-induced bone pain, EA electroacupuncture, WAA wrist-ankle acupuncture 

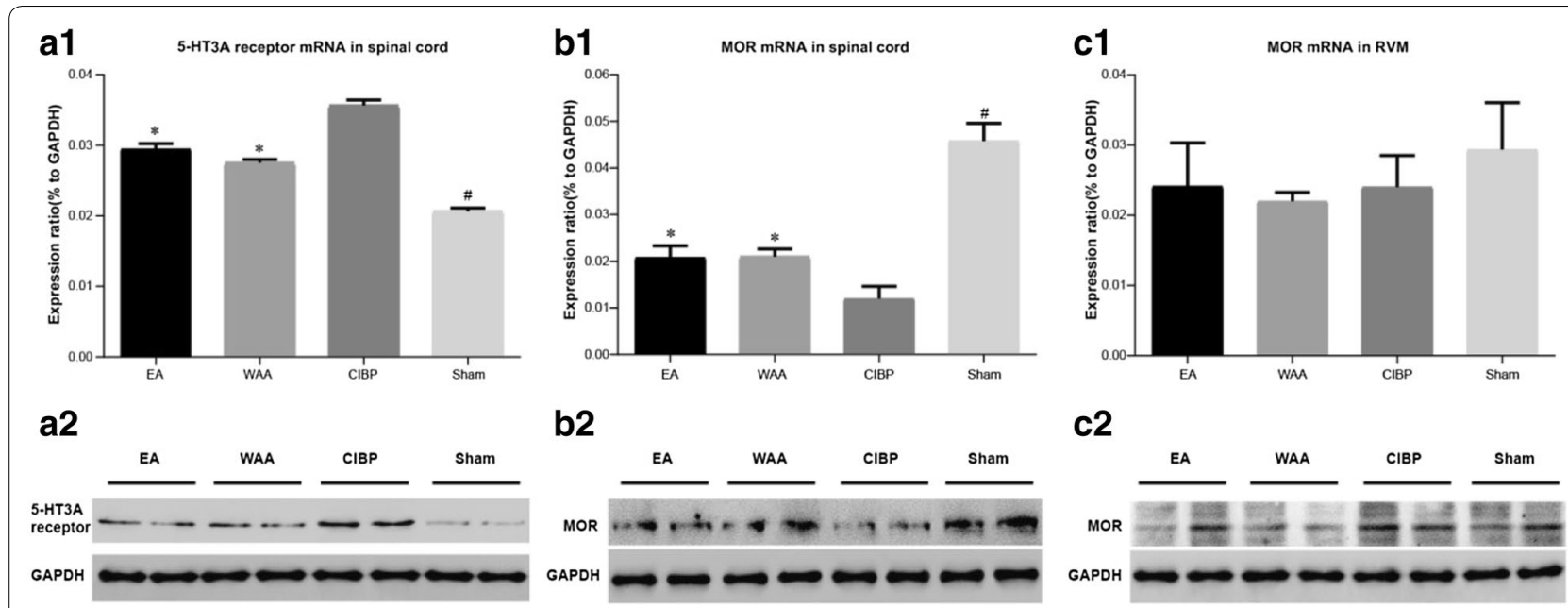

b2

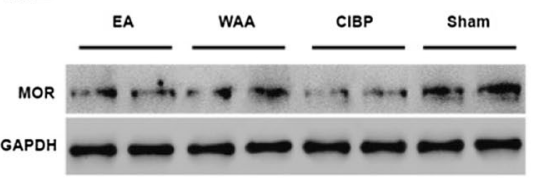

c2
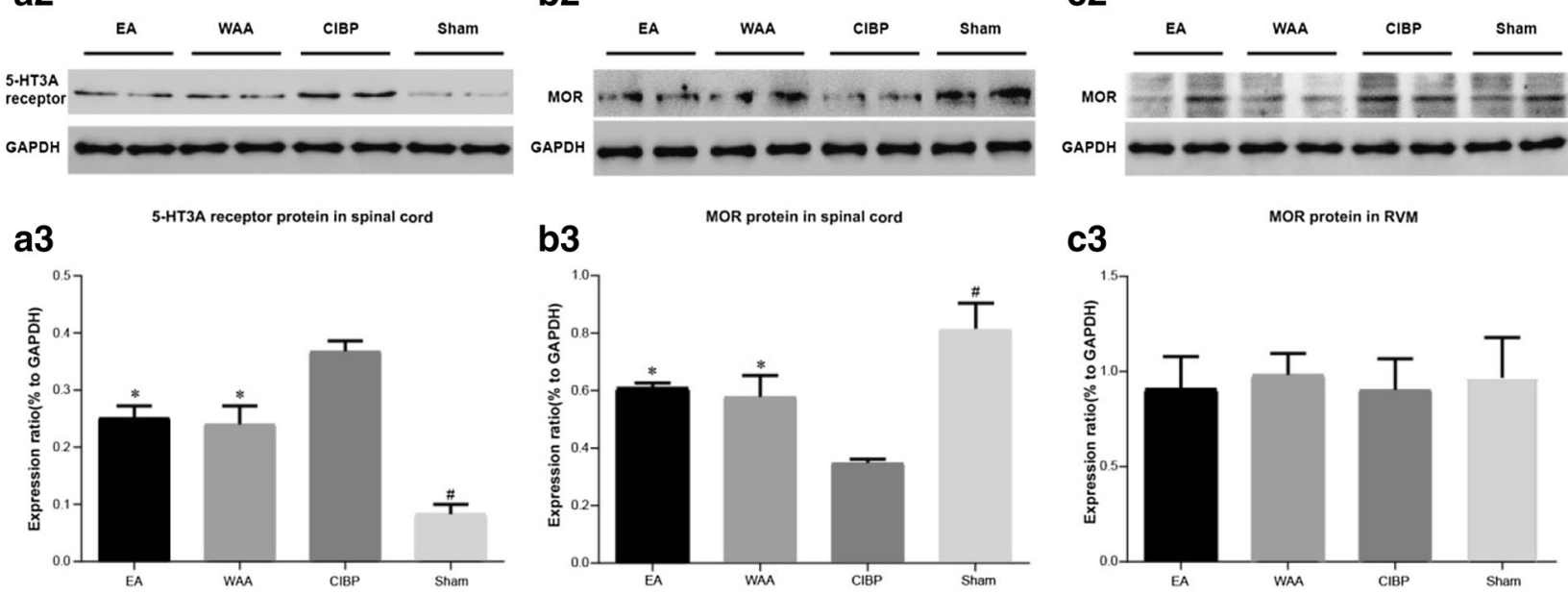

Fig. 5 Effects of WAA on $5-\mathrm{HT}_{3 A} R$ and MOR. Values are mean \pm standard deviations $(n=4) .{ }^{*} P<0.05$ vs. ClBP group; ${ }^{*} P<0.05$ vs. model groups $(C I B P$, $E A$, and WAA groups). CIBP cancer-induced bone pain, EA electroacupuncture, WAA wrist-ankle acupuncture, $5-H T_{3 A} R$ 5-hydroxytryotamine type $3 A$ receptor, MOR $\mu$-opioid receptor, RVM rostral ventromedial medulla, GAPDH glyceraldehyde-3-phosphate dehydrogenase

levels of 5-HT were significantly decreased by treatment with EA and WAA $(P<0.05$, Fig. $7 \mathrm{a} 1,2)$. Treatment of EA and WAA also resulted in a significant increase in EM-1 levels compared with the CIBP group $(P<0.05$, Fig. 7c1, 2). The expression levels of $\beta$-EP and EM-2 were both significantly decreased in the three model groups (CIBP, EA, and WAA groups) compared with the sham group $(P<0.05)$, but no significant difference was found among the model groups $(P>0.05$, Fig. $7 \mathrm{~b} 1,2$ and $\mathrm{d} 1,2)$, although a trend of an increasing effect of EA and WAA on the decreased levels induced by cancer pain was observed.

\section{Discussion}

Cancer-related pain resulting from bone metastasis has become the most common physical symptom in cancer patients that affects quality of life extremely. A rat model with site-specific metastases and similar pain symptoms to those of clinical patients, developed by Walker 256 mammary cancer cells injection into the tibial medullary cavity, is widely used for the study of cancer pain [35, 43]. The resultant tumor formation leads to bone trabecular degradation and site-specific nocifensive behavior formation. This model has closely mimicked the human pathophysiology of CIBP, involving inflammatory, neuropathic, and tumorigenic components, and revealed endogenous effectors of several targets in the periphery and at the levels of spinal cord and brain [44].

Consistent with previous reports [25, 35], it was observed in our experiment that intra-tibial injection of Walker 256 mammary cancer cells successfully led to progressive weight loss, cancer-related bone destruction, and elevated osteoclast activity. Our study also demonstrated increased pain thresholds in the CIBP rats after EA or WAA stimulation, attenuating hyperalgesia induced by bone metastasis, as shown by EA or WAA treatment that significantly increased the ipsilateral $50 \%$ PWT to the cancer cell inoculation compared with the sham control $(P<0.05)$. Analysis of the difference in analgesic effects between EA and WAA demonstrated that WAA produced a fast analgesic effect while EA $(2 / 100 \mathrm{~Hz})$ showed a comparatively slow analgesic potency (Fig. 3b). The application of WAA requires retaining needle for a long time, and the continuous stimulation may result 


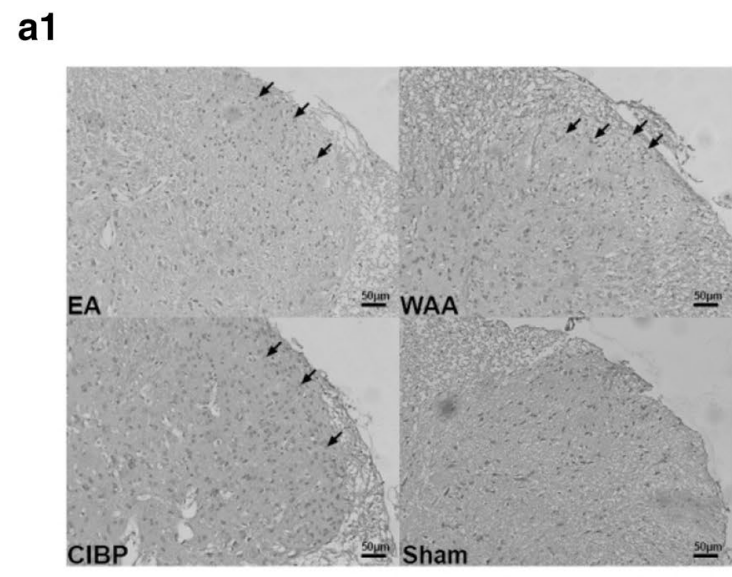

Immunohistochemical expression of $5-\mathrm{HT}_{3 \mathrm{~A}} \mathrm{R}$ in the SDH

\section{b1}

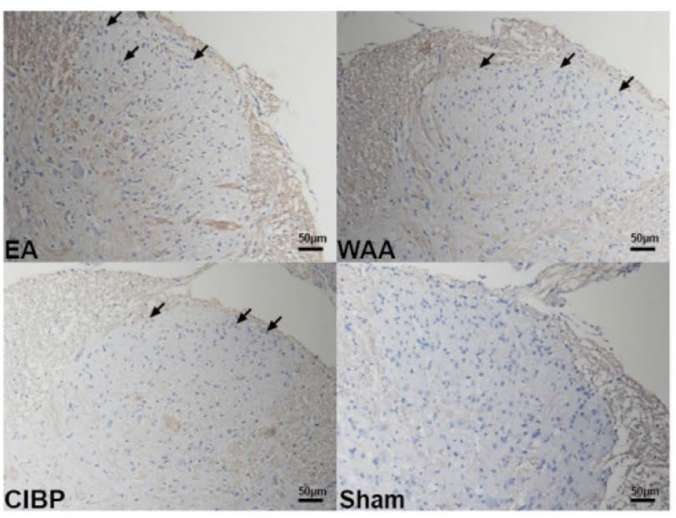

Immunohistochemical expression of MOR in the SDH

c1

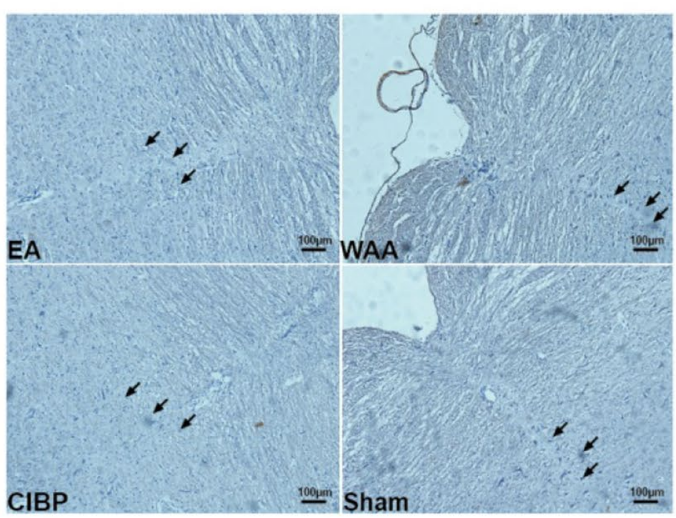

Immunohistochemical expression of MOR in the RVM a2

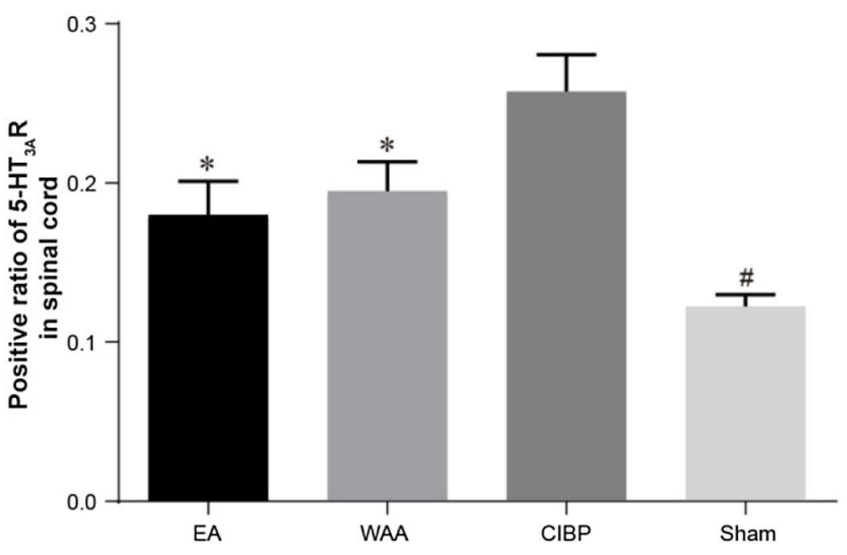

b2

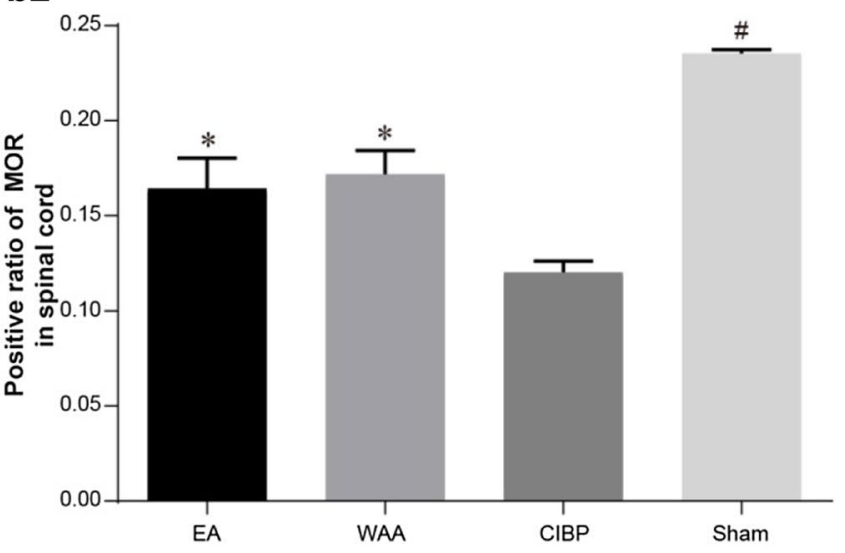

c2

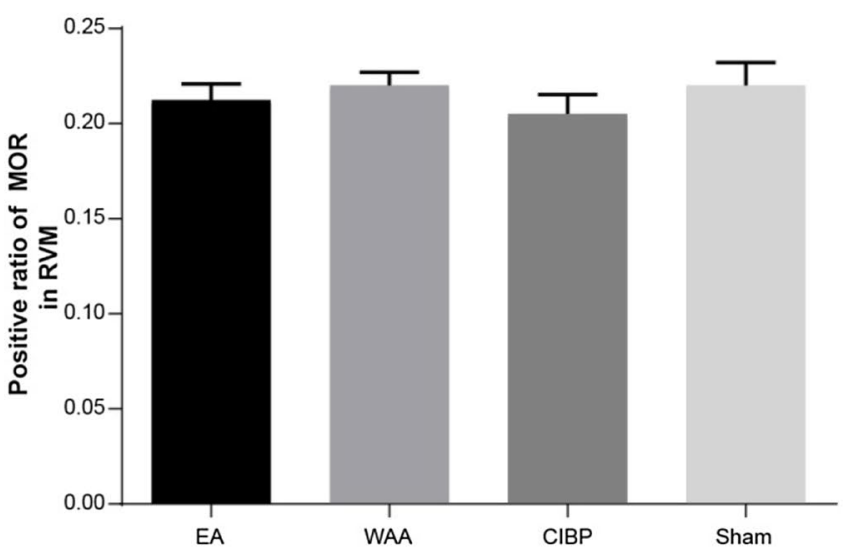

Fig. 6 Effects of WAA on $5-\mathrm{HT}_{3 \mathrm{~A}} \mathrm{R}$ and MOR immunohistochemical expression. Values are mean \pm standard deviations $(n=4)$ of positive proportion ${ }^{*} P<0.05$ vs. CIBP group; ${ }^{\#} P<0.05$ vs. model groups (CIBP, EA, and WAA groups). CIBP cancer-induced bone pain, EA electroacupuncture, WAA wristankle acupuncture, $5-H T_{3 A} R$ 5-hydroxytryotamine type $3 \mathrm{~A}$ receptor, MOR $\mu$-opioid receptor, SDH superficial layers of the dorsal horn, $R V M$ rostral ventromedial medulla 

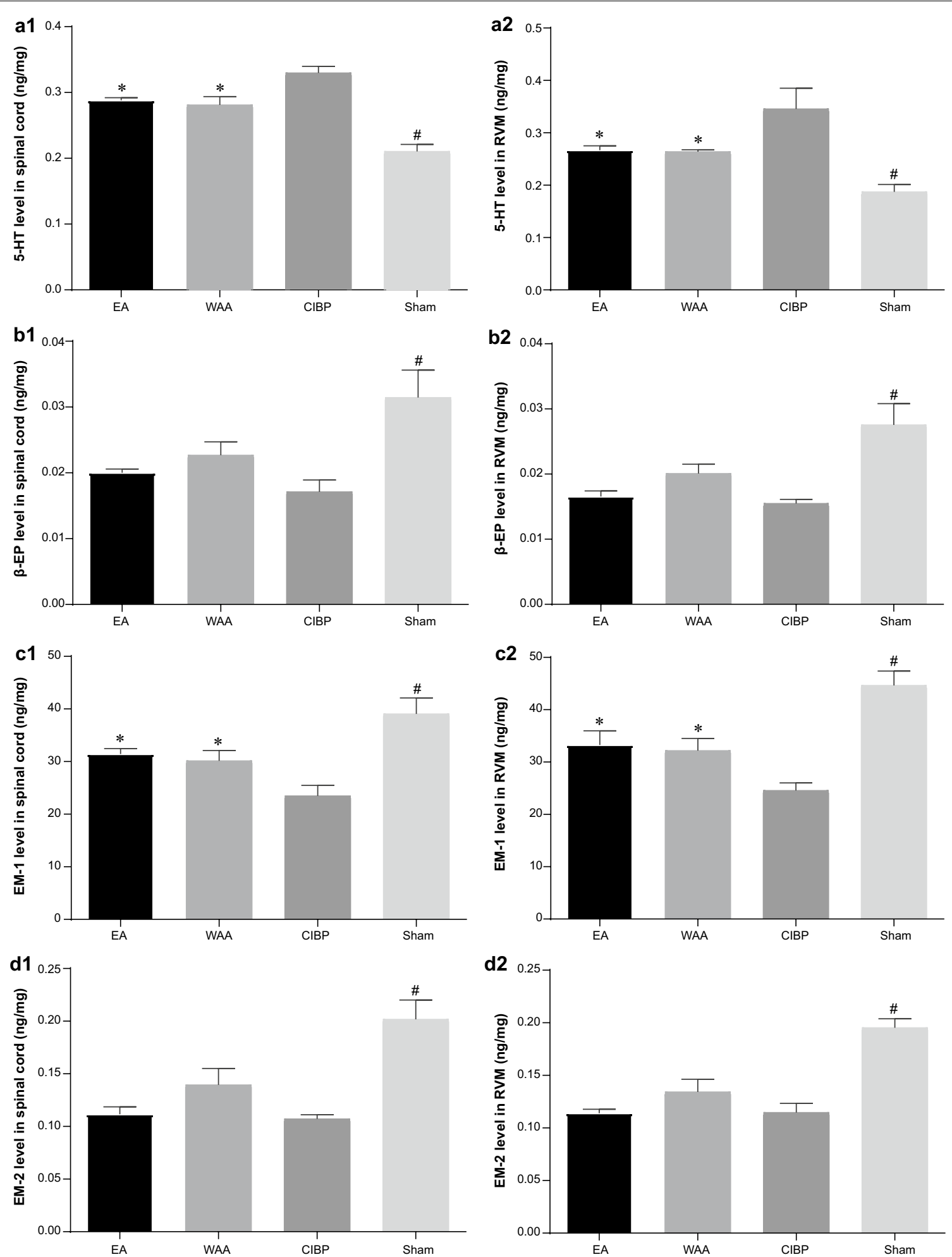

Fig. 7 Effects of WAA on 5-HT, $\beta-E P, E M-1$, and EM-2 levels. a1 Effects of WAA on 5-HT level in spinal cord; a2 Effects of WAA on 5-HT level in RVM; b1 Effects of WAA on $\beta$-EP level in spinal cord; $\mathbf{b} 2$ Effects of WAA on $\beta$-EP level in RVM; $\mathbf{c} 1$ Effects of WAA on EM-1 level in spinal cord; $\mathbf{c}$ Effects of WAA on EM-1 level in RVM; d1 Effects of WAA on EM-2 level in spinal cord; $\mathbf{d} 2$ Effects of WAA on EM-2 level in RVM. Values are mean \pm standard deviations ( $n=4$ ) of positive proportion. ${ }^{*} P<0.05$ vs. CIBP group; ${ }^{P} P<0.05$ vs. model groups (CIBP, EA, and WAA groups). CIBP cancer-induced bone pain, EA electroacupuncture, WAA wrist-ankle acupuncture, 5-HT 5-hydroxytryotamine, $\beta$-EP $\beta$-endorphin, EM-1 endomorphin-1, EM-2 endomorphin-2, RVM rostral ventromedial medulla 
in analgesic substances releasing earlier than EA, the mechanisms of which are still unknown and require further investigation. On day 15, ipsilateral 50\% PWT increased sharply in EA group, since electroacupuncture of $2 / 100 \mathrm{~Hz}$ can inhibit hyperalgesia and hypersensitivity caused by neuropathic pain, and stimulate the cumulative effect of multiple stimuli [45].

CIBP involves both inflammatory and neuropathic mechanisms, and the descending modulation in central nervous system may take a crucial role in the perception of such a chronic pain state. The RVM is one major final output of this endogenous descending modulation and takes part in persistent nociceptive transmission between the spinal cord and brain [46]. The RVM-spinal cord is a specific centrifugal pathway that either potentiates (descending facilitation) or suppresses (descending inhibition) nociceptive transmission [46-48]. Multiple transmitters and receptors in the RVM-spinal cord pathway are involved in the descending facilitation/inhibition system [48].

It has been systemically investigated that upregulation of 5-HT levels in the spinal cord by the descending pain facilitatory system participates in the development of CIBP [20,31]. 5-HT also exists in RVM neurons, and its increasing expression in RVM of CIBP rats has been reported in the previous study [20]. The main receptor subtype of $5-\mathrm{HT}$ concentrated in $\mathrm{SDH}$ is $5-\mathrm{HT}_{3 \mathrm{~A}} \mathrm{R}$, which is located on primary afferent $\mathrm{C}$ fiber terminals [49]. Activation of serotonin-positive neurons in the RVM leads to the descending of 5-HT to the spinal cord and then binding to $5-\mathrm{HT}_{3 \mathrm{~A}} \mathrm{R}$.

Our ELISA results suggest that 5-HT release was increased in both spinal cord and RVM of CIBP rats, and both EA and WAA counteracted the cancer-driven upregulation of 5-HT $(P<0.05)$ in spinal cord and RVM. Western blotting and immunohistochemistry results demonstrated that $5-\mathrm{HT}_{3 \mathrm{~A}} \mathrm{R}$ in the spinal cord was upregulated in the CIBP group, and both EA and WAA counteracted this cancer-driven upregulation $(P<0.05)$.

RVM neurons of the descending pain inhibition system expressing MOR contribute to the maintenance and perception of neuropathic pain [50]. Selective blocking of descending facilitation-targeting MOR-positive neurons in the RVM effectively reduced the nociceptive hypersensitivity of CIBP rats [51]. Mice with MOR gene knockout showed no response to morphine [52]. The main endogenous ligands of MOR are EM (including EM-1 and EM-2) and $\beta$-EP. EM1 and EM2 display potent opioid activity and bind to MOR with high selectivity and affinity, and thus they are regarded as endogenous specific ligands for MOR [53-56]. The body produces $\beta$-EP, a peptide with a stronger analgesic effect than morphine, to suppress early pain, but as the pain continues the secretion of $\beta$-EP decreases gradually. Like EM, $\beta$-EP exerts its actions via MOR.

The release of MOR, as well as EM1, EM2, and $\beta$-EP, both in the spinal cord and in the RVM, was observed in our study. MOR was downregulated only in the spinal cord (SDH) in the CIBP group, and both EA and WAA counteracted this cancer-driven downregulation $(P<0.05)$, while no significant difference of MOR in the RVM was identified among the four groups. EA or WAA also counteracted the cancer-driven downregulation of EM-1 $(P<0.05)$ in the RVM and spinal cord. $\beta$-EP and EM-2 in the RVM and spinal cord were decreased remarkably in the CIBP group, but neither EA or WAA showed a significant effect on $\beta$-EP and EM-2, although a trend of increasing effect was observed (Fig. 7).

Considering these results, the anti-nociceptive effect of acupuncture is related to the facilitation/inhibition of 5-HT and MOR in the RVM-spinal cord pathway, which could be the target of analgesic treatment. Zhang et al. [29] found RVM MORs contributed to EA anti-hyperalgesia in a rat model with inflammatory pain. RVM MORs are mainly expressed in $\gamma$-aminobutyric acid (GABA) neurons, and GABA(A) receptor in the RVM is located on 5-HT neurons. The prolonged tail-flick latency induced by micro-injection of MOR agonist in the RVM was antagonized by intrathecal pretreatment with 5-HT antagonist [30]. One of the underlying mechanisms of the decrease in hyperalgesia after treatment with WAA and EA observed in our study may be that the decreased expression of 5-HT in the RVM inhibited pain facilitation, reducing 5-HT levels in the spinal cord, and downregulating $5-\mathrm{HT}_{3 \mathrm{~A}} \mathrm{R}$ activation.

Another mechanism may be related to the expression of MOR in the descending pain inhibition system. In our study, the decreased MOR in the spinal cord induced by CIBP was significantly increased by EA or WAA treatment. But MOR in the RVM did not decrease significantly after cancer cell inoculation, inconsistent with previous reports [57]. This may be because CIBP had not yet exerted a significant effect on the RVM due to the limited observation time. However, an increase in EM-1 in both the RVM and spinal cord was observed after WAA and EA treatment, contributing to the analgesic effects of WAA and EA. However, WAA and EA did not reverse the decrease in $\beta$-EP and EM-2 in the RVM and spinal cord in CIBP rats, inconsistent with other studies on acupuncture analgesia $[14,58-60]$. Although we did not identify a statistically significant effect of EA or WAA on $\beta$-EP and EM-2, a trend of an increasing effect of EA and WAA was observed (Fig. 7). The reason for this may be connected to the small sample size that can hardly produce a statistically significant result. 
In general, our findings of the present study indicated that mechanical hyperalgesia of CIBP rats could be suppressed by both EA and WAA, and WAA had a faster analgesic potency. Moreover, the analgesic mechanism of WAA in the CIBP rats may be the same as that of EA. The effect of WAA in raising the pain threshold of CIBP rats may be achieved by inhibiting the expression of $5-\mathrm{HT}$ in the spinal cord and RVM, inhibiting the expression of $5-\mathrm{HT}_{3 \mathrm{~A}} \mathrm{R}$ in the spinal cord, increasing the expression of MOR in the spinal cord, and increasing EM-1 in the spinal cord and RVM; it is not clear whether any effects of WAA on the expression of MOR in the RVM and the expression of $\beta$-EP and EM- 2 in the RVM and spinal cord exist.

Nevertheless, there are some limitations to our study. A statistically significant effect of EA or WAA on $\beta$-EP and EM-2 was not observed due to the small sample size, and the effect of WAA and EA on the expression of MOR in RVM of CIBP rats was not observed because of the limited experimental time, which will be extended in our future studies. The results of this animal experiment may not be able to be generalized to humans.

\section{Conclusions}

WAA, a special acupuncture therapy performed only on the wrist and ankle, could significantly alleviate mechanical hyperalgesia in CIBP rats compared with EA, at least in part, by regulating of the descending pain-modulating system. This mechanism can be explained as suppressing the expression of $5-\mathrm{HT}$ and $5-\mathrm{HT}_{3 \mathrm{~A}} \mathrm{R}$, and increasing the expression of MOR and its ligand EM-1 in the RVM-spinal cord pathway. Furthermore, WAA produced a quicker analgesic effect than EA, the mechanisms of which may be related to retaining needle of WAA but require further investigation. WAA has been widely accepted for its ease of use and its remarkable effect in pain relief. The data from the present study provide experimental support for future research.

\begin{abstract}
Abbreviations
WAA: wrist-ankle acupuncture; EA: electroacupuncture; CIBP: cancer-induced bone pain; MHT: mechanical hyperalgesia threshold; PWT: paw withdrawal threshold; RVM: rostral ventromedial medullar; $5-\mathrm{HT}_{3 \mathrm{~A}} \mathrm{R}$ : 5 -hydroxytryotamine type 3 A receptor; MOR: $\mu$-opioid receptor; $\beta$-EP: $\beta$-endorphin; EM: endomorphin; ST36: Zusanli; BL60: Kunlun; ANOVA: one-way analysis of variance.
\end{abstract}

\section{Acknowledgements}

We thank Animal Experimentation Center of Changhai Hospital for expert technical assistance.

\section{Authors' contributions}

WL, XM and QZ substantially contributed to study concept, design and results interpretation. CZ and XZ participated in behavioral tests, H\&E staining, immunohistochemical staining, real-time PCR, western blot and ELISA. CX involved in model inducing, WAA treatment, EA treatment, data analysis and drafting the article. All authors critically discussed the results and revised the manuscript for important intellectual content. CZ and CX contributed equally to this article. All authors read and approved the final manuscript.

\section{Funding}

This work was supported by the National Natural Science Foundation of China (Grant No. 81373756).

\section{Availability of data and materials}

The datasets used or analyzed during the current study are available from the corresponding author on reasonable request.

\section{Ethics approval and consent to participate}

The study protocol and experiments were approved by the Animal Care and Use Committee of Naval Military Medical University (Shanghai, China).

\section{Consent for publication}

Not applicable.

\section{Competing of interests}

The authors declare that they have no competing interests.

\section{Author details}

${ }^{1}$ School of Traditional Chinese Medicine, Changhai Hospital, Naval Medical University, 168 Changhai Road, Shanghai 200433, People's Republic of China.

${ }^{2}$ Laboratory of Neuronal Network and Systems Biology, Shanghai Medical College, Fudan University, Shanghai 200032, China. ${ }^{3}$ Department of Anesthesiology, Eastern Hepatobiliary Surgery Hospital, Naval Medical University, 225

Changhai Road, Shanghai 200433, People's Republic of China.

Received: 4 November 2019 Accepted: 9 January 2020

Published online: 04 February 2020

\section{References}

1. Foley KM. Treatment of cancer-related pain. J Natl Cancer Inst Monogr. 2004;32:103-4.

2. Coleman RE. Clinical features of metastatic bone disease and risk of skeletal morbidity. Clin Cancer Res. 2006;12(20 Pt 2):6243s-9s.

3. Colvin L, Fallon M. Challenges in cancer pain management-bone pain. Eur J Cancer. 2008;44(8):1083-90.

4. Falk S, Dickenson AH. Pain and nociception: mechanisms of cancerinduced bone pain. J Clin Oncol. 2014;32(16):1647-54.

5. Fallon M, Hoskin PJ, Colvin LA, Fleetwood-Walker SM, Adamson D, Byrne A, et al. Randomized double-blind trial of pregabalin versus placebo in conjunction with palliative radiotherapy for cancer-Induced bone pain. J Clin Oncol. 2016;34(6):550-6.

6. Fernandes C, Monteiro S, Belchior A, Marques F, Gano L, Correia JD, et al. Novel (188)Re multi-functional bone-seeking compounds: synthesis, biological and radiotoxic effects in metastatic breast cancer cells. Nucl Med Biol. 2016:43(2):150-7.

7. Meuser T, Pietruck C, Radbruch L, Stute P, Lehmann KA, Grond S. Symptoms during cancer pain treatment following WHO-guidelines: a longitudinal follow-up study of symptom prevalence, severity and etiology. Pain. 2001;93(3):247-57.

8. Koyyalagunta D, Bruera E, Solanki DR, Nouri KH, Burton AW, Toro MP, et al. A systematic review of randomized trials on the effectiveness of opioids for cancer pain. Pain Phys. 2012;15(3 Suppl):ES39-58.

9. Lao L, Zhang RX, Zhang G, Wang X, Berman BM, Ren K. A parametric study of electroacupuncture on persistent hyperalgesia and Fos protein expression in rats. Brain Res. 2004;1020(1-2):18-29.

10. Ling CQ, Zhou QH, Gu W. Wrist-ankle acupuncture. Shanghai: Shanghai Scientific \& Technical Publishers; 2017. p. 1-28.

11. Zhang XS, Ling CQ, Zhou QH. Practical wrist-ankle acupuncture therapy. Beijing: People's Medical Publishing House; 2002. p. 1-39.

12. Zeng K, Dong HJ, Chen HY, Chen Z, Li B, Zhou QH. Wrist-ankle acupuncture for pain after transcatheter arterial chemoembolization in patients with liver cancer: a randomized controlled trial. Am J Chin Med. 2014;42(2):289-302. 
13. Hu X, Ling CQ, Zhou QH. Clinical observation on Wrist-ankle acupuncture for treatment of pain of middle-late liver cancer. Chin Acupunct Moxibustion. 2004;24(3):149-51.

14. Hu X, Gu W, Zhou QH, Ling CQ. Analgesic efficacy and mechanism of wrist-ankle acupuncture on pain caused by liver cancer. Chin J Integr Trad West Med Liver Dis. 2005;15(3):131-3.

15. Zhou QH, Hu X, Gu W. Clinical observation on efficacy of wrist-ankle acupuncture in reliveing moderate and severe pain of patients with liver cancer. J Zhejiang Coll Tradit Chin Med. 2005;43(1):53-5.

16. Mantyh WG, Jimenez-Andrade JM, Stake Jl, Bloom AP, Kaczmarska MJ, Taylor RN, et al. Blockade of nerve sprouting and neuroma formation markedly attenuates the development of late stage cancer pain. Neuroscience. 2010;171(2):588-98.

17. O'Donnell PW, Clohisy DR. Biology of bone cancer pain. In: Randall RL, editor. Metastatic bone disease: an integrated approach to patient care. New York: Springer; 2016. p. 37-44.

18. Calejesan AA, Kim SJ, Zhuo M. Descending facilitatory modulation of a behavioral nociceptive response by stimulation in the adult rat anterior cingulate cortex. Eur J Pain. 2000;4(1):83-96.

19. Suzuki R, Rahman W, Hunt SP, Dickenson AH. Descending facilitatory control of mechanically evoked responses is enhanced in deep dorsal horn neurones following peripheral nerve injury. Brain Res. 2004;1019(1-2):68-76.

20. Huang ZX, Lu ZJ, Ma WQ, Wu FX, Zhang YQ, Yu WF, et al. Involvement of RVM-expressed P2X7 receptor in bone cancer pain: mechanism of descending facilitation. Pain. 2014;155(4):783-91.

21. Urban MO, Gebhart GF. Supraspinal contributions to hyperalgesia. Proc Natl Acad Sci USA. 1999;96(14):7687-92.

22. Ossipov MH, Dussor GO, Porreca F. Central modulation of pain. J Clin Invest. 2010;120(11):3779-87.

23. Ossipov MH, Lai J, Malan TP Jr, Porreca F. Spinal and supraspinal mechanisms of neuropathic pain. Ann NY Acad Sci. 2000;909:12-24.

24. Zhang RX, Li A, Liu B, Wang L, Ren K, Qiao JT, et al. Electroacupuncture attenuates bone cancer pain and inhibits spinal interleukin-1 beta expression in a rat model. Anesth Analg. 2007;105(5):1482-8.

25. Zhang RX, Li A, Liu B, Wang L, Xin J, Ren K, et al. Electroacupuncture attenuates bone-cancer-induced hyperalgesia and inhibits spinal preprodynorphin expression in a rat model. Eur J Pain. 2008;12(7):870-8.

26. Han JS. Acupuncture and endorphins. Neurosci Lett. 2004;361(1-3):258-61.

27. Han JS. Acupuncture: neuropeptide release produced by electrical stimulation of different frequencies. Trends Neurosci. 2003;26(1):17-22.

28. Lin JG, Chen WL. Acupuncture analgesia: a review of its mechanisms of actions. Am J Chin Med. 2008;36(4):635-45.

29. Zhang Y, Li A, Lao L, Xin J, Ren K, Berman BM, et al. Rostral ventromedial medulla mu, but not kappa, opioid receptors are involved in electroacupuncture anti-hyperalgesia in an inflammatory pain rat model. Brain Res. 2011;1395:38-45.

30. Hurley RW, Banfor P, Hammond DL. Spinal pharmacology of antinociception produced by microinjection of mu or delta opioid receptor agonists in the ventromedial medulla of the rat. Neuroscience. 2003;118(3):789-96.

31. Donovan-Rodriguez T, Urch CE, Dickenson AH. Evidence of a role for descending serotonergic facilitation in a rat model of cancer-induced bone pain. Neurosci Lett. 2006;393(2-3):237-42.

32. Liang Y, Du JY, Fang JF, Fang RY, Zhou J, Shao XM, et al. Alleviating mechanical allodynia and modulating cellular immunity contribute to electroacupuncture's dual effect on bone cancer pain. Integr Cancer Ther. 2018;17(2):401-10.

33. Paxinos G, Watson C. Rat brain in stereotaxic coordinates. Salt Lake City: Academic Press; 1997

34. Wang XW, Hu S, Mao-Ying QL, Li Q, Yang CJ, Zhang H, et al. Activation of c-jun $\mathrm{N}$-terminal kinase in spinal cord contributes to breast cancer induced bone pain in rats. Mol Brain. 2012;5:21.

35. Mao-Ying QL, Zhao J, Dong ZQ, Wang J, Yu J, Yan MF, et al. A rat model of bone cancer pain induced by intra-tibia inoculation of Walker 256 mammary gland carcinoma cells. Biochem Biophys Res Commun. 2006;345(4):1292-8.

36. Zhang Z, Wang C, Gu G, Li H, Zhao H, Wang K, et al. The effects of electroacupuncture at the ST36 (Zusanli) acupoint on cancer pain and transient receptor potential vanilloid subfamily 1 expression in Walker 256 tumor-bearing rats. Anesth Analg. 2012;114(4):879-85.

37. Zhang CP, Zhang XW, Zhou QH, Ma LS, Han YY, Inventors. An improved head fixation device for rats. China patent CN 201621273938.1. 2017-10-03.

38. Dixon WJ. Efficient analysis of experimental observations. Annu Rev Pharmacol Toxicol. 1980;20:441-62.

39. Chaplan SR, Bach FW, Pogrel JW, Chung JM, Yaksh TL. Quantitative assessment of tactile allodynia in the rat paw. J Neurosci Methods. 1994;53(1):55-63.

40. Lin W, Zhong M, Liang S, Chen Y, Liu D, Yin Z, et al. Emodin inhibits migration and invasion of MHCC-97H human hepatocellular carcinoma cells. Exp Ther Med. 2016;12(5):3369-74.

41. Dubin AE, Huvar R, D'Andrea MR, Pyati J, Zhu JY, Joy KC, et al. The pharmacological and functional characteristics of the serotonin 5-HT(3A) receptor are specifically modified by a 5-HT(3B) receptor subunit. J Biol Chem. 1999;274(43):30799-810.

42. Wu ZS, Cui ZC, Cheng H, Fan C, Melcher K, Jiang Y, et al. High yield and efficient expression and purification of the human 5-HT3A receptor. Acta Pharmacol Sin. 2015;36(8):1024-32.

43. Schwei MJ, Honore P, Rogers SD, Salak-Johnson JL, Finke MP, Ramnaraine $\mathrm{ML}$, et al. Neurochemical and cellular reorganization of the spinal cord in a murine model of bone cancer pain. J Neurosci. 1999;19(24):10886-97.

44. Shenoy PA, Kuo A, Vetter I, Smith MT. The walker 256 breast cancer cellinduced bone pain model in rats. Front Pharmacol. 2016;7:286.

45. Du JY, Chen YT, Wu SF, Fang JF, Liang Y, Fang JQ. Screen the parameter of electroacupuncture's analgesic aftereffect on bone cancer pain. Zhongguo Zhong Yi Yao Za Zhi. 2014;29(5):1454-8.

46. Bee LA, Dickenson AH. Rostral ventromedial medulla control of spinal sensory processing in normal and pathophysiological states. Neuroscience. 2007;147(3):786-93.

47. Mansikka H, Zhao C, Sheth RN, Sora I, Uhl G, Raja SN. Nerve injury induces a tonic bilateral mu-opioid receptor-mediated inhibitory effect on mechanical allodynia in mice. Anesthesiology. 2004;100(4):912-21.

48. Millan MJ. Descending control of pain. Prog Neurobiol. 2002;66(6):355-474

49. Morales M, Battenberg E, Bloom FE. Distribution of neurons expressing immunoreactivity for the $5 \mathrm{HT} 3$ receptor subtype in the rat brain and spinal cord. J Comp Neurol. 1998;402(3):385-401.

50. Mase H, Sakai A, Sakamoto A, Suzuki H. A subset of mu-opioid receptorexpressing cells in the rostral ventromedial medulla contribute to thermal hyperalgesia in experimental neuropathic pain. Neurosci Res. 2011;70(1):35-43.

51. Cao F, Chen SS, Liu XJ, Xiao XP, Yang SP, Xu AJ, et al. Analgesic effects of the selective blocking of descending facilitation targeting $\mu$ opioid receptor positive neurons in a rat model of bone cancer pain. Chin J Anesthesiol. 2009;29(11):992-6.

52. Matthes HWD, Maldonado R, Simonin F, Valverde O, Slowe S, Kitchen I, et al. Loss of morphine-induced analgesia, reward effect and withdrawal symptoms in mice lacking the $\mu$-opioid-receptor gene. Nature. 1996;383(6603):819-23.

53. De Marco R, Janecka A. Strategies to improve bioavailability and in vivo efficacy of the endogenous opioid peptides endomorphin-1 and endomorphin-2. Curr Top Med Chem. 2015;16(2):141-55.

54. Gong J, Strong JA, Zhang S, Yue X, DeHaven RN, Daubert JD, et al. Endomorphins fully activate a cloned human mu opioid receptor. FEBS Lett. 1998;439(1-2):152-6.

55. Hackler L, Zadina JE, Ge LJ, Kastin AJ. Isolation of relatively large amounts of endomorphin-1 and endomorphin-2 from human brain cortex. Peptides. 1997;18(10):1635-9.

56. Han Z, Jiang YH, Wan Y, Wang Y, Chang JK, Han JS. Endomorphin-1 mediates $2 \mathrm{~Hz}$ but not $100 \mathrm{~Hz}$ electroacupuncture analgesia in the rat. Neurosci Lett. 1999;274(2):75-8.

57. Yamamoto J, Kawamata T, Niiyama Y, Omote K, Namiki A. Down-regulation of mu opioid receptor expression within distinct subpopulations of dorsal root ganglion neurons in a murine model of bone cancer pain. Neuroscience. 2008;151(3):843-53.

58. Liang FR, Liu YX, Chen J, Luo R. The relationship between the after effect of electroacupuncture analgesic and the contents of 5-HT in the brain stem and $\beta-E P$ in hypothalamus. Shanghai J Acupunct Moxibustion. 2001:20(3):37-9. 
59. Clement-Jones V, McLoughlin L, Tomlin S, Besser GM, Rees LH, Wen HL. Increased beta-endorphin but not met-enkephalin levels in human cerebrospinal fluid after acupuncture for recurrent pain. Lancet. 1980;2(8201):946-9.

60. Jia WH, Chi WY, Lou C, Wang GZ. Effect of electroacupuncture intervention on beta-endorphin levels of hypothalamus and spinal cord tissues in rats with pelmatic incisional pain. Zhen Ci Yan Jiu. 2016;41(3):225-9.

\section{Publisher's Note}

Springer Nature remains neutral with regard to jurisdictional claims in published maps and institutional affiliations.
Ready to submit your research? Choose BMC and benefit from:

- fast, convenient online submission

- thorough peer review by experienced researchers in your field

- rapid publication on acceptance

- support for research data, including large and complex data types

- gold Open Access which fosters wider collaboration and increased citations

- maximum visibility for your research: over 100M website views per year

At BMC, research is always in progress.

Learn more biomedcentral.com/submissions 